\title{
General Practice as a career choice among undergraduate medical students in Greece
}

\author{
Anargiros Mariolis*1, Constantinos Mihas ${ }^{1}$, Alevizos Alevizos ${ }^{1}$, \\ Vasilis Gizlis ${ }^{1}$, Theodoros Mariolis ${ }^{1}$, Konstantinos Marayiannis ${ }^{1}$, \\ Yiannis Tountas ${ }^{2}$, Christodoulos Stefanadis ${ }^{3}$, Anastas Philalithis ${ }^{4}$ and \\ George Creatsas ${ }^{5}$
}

\begin{abstract}
Address: ${ }^{1}$ Department of General Practice/Family Medicine, Health Centre of Vyronas, Athens, Greece, ${ }^{2}$ Divisions of Hygiene and Epidemiology, Department of Social Medicine, School of Medicine, University of Athens, Greece, ${ }^{3}$ Section of Preventive Cardiology, Department of Cardiology, Vice-president of Medical School, School of Medicine, University of Athens, Greece, ${ }^{4}$ Division of Health Planning, Department of Social Medicine, School of Medicine, University of Crete, Greece and ${ }^{5}$ 2nd Department of Obstetrics and Gynaecology, Dean of School of Medicine, University of Athens, Greece

Email: Anargiros Mariolis* - anargirosm@yahoo.gr; Constantinos Mihas - gas521@yahoo.co.uk; Alevizos Alevizos - alevisos@gmail.com; Vasilis Gizlis - info@ hcvyrona.gr; Theodoros Mariolis - mariolis@hcvyrona.gr; Konstantinos Marayiannis - info@hcvyrona.gr; Yiannis Tountas - info@hcvyrona.gr; Christodoulos Stefanadis - info@hcvyrona.gr; Anastas Philalithis - info@hcvyrona.gr; George Creatsas - info@hcvyrona.gr

* Corresponding author
\end{abstract}

Published: I June 2007

BMC Medical Education 2007, 7:15 doi:10.1186/1472-6920-7-15
Received: 25 August 2006

Accepted: I June 2007

This article is available from: http://www.biomedcentral.com/1472-6920/7//5

(C) 2007 Mariolis et al; licensee BioMed Central Ltd.

This is an Open Access article distributed under the terms of the Creative Commons Attribution License (http://creativecommons.org/licenses/by/2.0), which permits unrestricted use, distribution, and reproduction in any medium, provided the original work is properly cited.

\begin{abstract}
Background: Although General Practice (GP) was recognized as a medical specialty in Greece in 1986, the number of GPs is insufficient to cover needs and only few medical graduates choose GP as a career option. In the present study we investigated the profile of medical students in terms of their decisions regarding specialization and the possible association of career choices different from GP with the status of undergraduate training regarding GP.
\end{abstract}

Methods: The sample consisted of final year students in the Medical School of the University of Athens, Greece. Students filled in a self-reported questionnaire focusing on medical specialization, and GP in particular.

Results: Response rate was $82.5 \%$ with 1021 questionnaires collected, out of 1237 eligible medical students. Only 44 out of the 1021 (4.3\%) respondents stated that GP is -or could be- among their choices for specialty. The most popular medical specialty was General Surgery ( $10.9 \%)$, followed by Cardiology $(9.6 \%)$, Endocrinology ( $8.7 \%$ ) and Obstetrics-Gynaecology (8.3\%). The most common criterion for choosing GP was the guaranteed employment on completion of the residency (54.6\%) while a $56.6 \%$ of total respondents were positive to the introduction of GP/FM as a curriculum course during University studies.

Conclusion: Despite the great needs, GP specialty is currently not a career option among undergraduate students of the greater Medical University in Greece and is still held in low esteem. A university department responsible for undergraduate teaching, promotion and research in GP (where not available) is essential; the status of undergraduate training in general practice/family medicine seems to be one of the most important factors that influence physician career choices regarding primary care specialties. 


\section{Background}

The necessity of implementing innovative and developmental changes in primary care is of great importance, since the need for effective and efficient primary health care services worldwide, is imperative. One of the keyissues in improving the future care services is the human resources sector, which in practical terms is actually reflected in the number of medical students who choose General Practice/Family Medicine (GP/FM) as a specialty. There is a progressive decline in the number of physicians who choose GP/FM as a specialty in most countries worldwide, and many countries have recently increased GP's annual wages in order to attract postgraduate students in their residency training programmes. One of the most important factors that influences and promotes medical students in choosing a primary care specialty seems to be the undergraduate training programme. In Greece where we conducted our survey, according to the national medical specialties legislation, medical graduates register for the chosen specialty area and wait for a post opening. Depending on the popularity of the chosen specialty, a graduate may spend several years on a waiting list before beginning his/her residency. Even though there is a large need for General Practitioners [1], most of the medical students choose careers in other medical areas, a trend that is evident by the long waiting lists for residency entrance in all other specialties. Since 1986, when GP/FM was established as an independent medical specialty, the attention of policy makers was focused on how to direct new medical graduates to choose GP as a career in order to provide primary health care for the country's rural, and recently urban, population [2]. In Greek National Health System, General Practice and Family Medicine are considered as one medical specialty. General Practitioners/Family Physicians are totally and exclusively responsible for practicing Primary Health Care. However, the focus of policy on improving the training of General Practitioners and on providing incentives to make the career attractive did not extend to encourage the creation of departments of GP/FM in medical schools and the inclusion of General Practice or Primary Health Care in the medical curriculum. As a result, out of seven medical schools in the country, only the Faculty of Medicine of the University of Crete appointed, since it was established in 1984, academic staff in the discipline of Family Medicine [3] and has included a four-week clerkship in Primary Health Care in the final year of studies since the first group of students graduated in $1990[4,5]$. It should be stressed that although there is an increasing need for General Practitioners worldwide, few medical students are choosing this medical specialty at least in North America while its popularity varies in the United Kingdom. For example, as evidenced by the Canadian Residency Matching Service (CaRMS) reports, in $1982,40 \%$ of Canadian medical students made GP/FM their first choice for residency training [6-11]. In 1996, this proportion had fallen to $32 \%$ and by 2002 to $29 \%$. A similar picture is described in the United States [12-14]. There, the proportion of the medical school graduates selecting GP/FM fell from a peak of $17.3 \%$ in 1997 to $9.2 \%$ in 2003. Although there is a notable decline in the proportions of General Practitioners in the above two countries, such percentages are considered very high for the present situation in Greece. Currently, the proportion of medical students in Greece choosing GP/FM for specialization is as low as a $3.1 \%$ [15]. The reasons why medical school graduates do not choose GP/FM in Greece have not being investigated yet. It is speculated that part of the problem is due to the fact that the Greek healthcare system follows the trend towards super-specialized practice, made necessary by the explosion of new knowledge in the field of bio-medical research and made attractive by its better 'market value' [16]. However, the extremely low interest exhibited by Greek medical students is considered worthy of further investigation. It should be noted that at the present time in Greece, General Practitioners are the only medical specialists who have a secure career since they are appointed, immediately after accreditation as a specialist, to a tenured post in the Health Centres of the National Health System in rural Greece, where only approximately 1200 such posts out of 2700 are filled by specialists in GP. No other medical specialty has similar benefits in Greece today. The purpose of this study was to investigate the profile of senior medical students in the largest medical school in Greece, the Medical School of the University of Athens (Athens accounts for almost half the country's population and for the half of students in medical schools nationwide), in terms of specialization issues, to explore the reasons why GP/FM is held in such a low status as a specialty among medical students in Greece, as well as to investigate on the possible relation between undergraduate training programmes and career choices regarding primary care specialties.

\section{Methods \\ Subjects}

The target group consisted of students from the Medical School in the University of Athens. All medical students who were in the sixth final year of their academic studies and all graduating students who had not successfully completed their studies during the predefined 6 years of the Athens' medical school curriculum were invited to answer a questionnaire, described in detail below.

\section{Survey instrument and procedure}

The survey instrument was a purpose-made, self-reported questionnaire with both closed and open-ended questions. The questionnaires were delivered after acquiring verbal consent. Apart from completing basic personal socio-demographic data, students were asked whether they had already chosen the medical residency they would 
like to follow and if yes, which would it be. Age, gender, parents' profession were self reported. The area of origin was also self-reported. After collecting the data, the classification of area to urban, rural or semi-urban was based on the Greek National Census of 2001[17]. Students who had not chosen yet their area of medical residency could indicate which specialties were in their first three choices, in an open-ended fashion. The questionnaire also included a question regarding the reasons for choosing a medical specialty. Here students could choose only one of four predefined answers (salary, scientific interest, low time to wait and social and professional prestige) or write in their own reason (again only one). Other items of the questionnaire referred to the sources of information and factors influencing their choice of medical specialty and GP/FM in particular. Students were also asked about the potential problems they were feeling they might encounter during their residency, what they believe is the best method for selecting new residents (e.g. waiting lists, exams etc.), the health care structure they would like to work at after finishing the residency and finally whether or not they are feeling satisfied with the choice to study medicine. All questions were closed-ended and the participants were invited to select only one of the predefined options. A second part of the questionnaire was devoted to issues more specifically related to GP/FM. There were questions about whether they were aware of GP/FM as a medical specialty and if respondents would be interested in choosing GP/FM. They also had to indicate the reasons for not choosing GP/FM as their specialty and the main sources of information about specialization in GP/FM. Again, the answers were pre-defined and the students were invited to choose the one that fitted the best to their opinion. Students were also asked to choose one of four proposed definitions of GP/FM, of which only one was correct. The 4 definitions of General Practice the medical student was invited to choose were: a) General approach of Medicine with basic knowledge of the main Medical specialties, b) First aid to emergency medical situations in removed regions, c) Humanistic oriented approach of Medicine with aim to prevent, treat and rehabilitate and d) Primary care of usual medical problems and reference to the suitable expert. The $3^{\text {rd }}$ definition was considered correct. Finally, students were asked to estimate the number of General Practitioners needed currently in Greece, and express an opinion about the usefulness of including GP/FM in the undergraduate course. The University of Athens ethics committee has examined and approved the protocol of our study regarding Helsinki Declaration about ethical principles for medical research involving human subjects. The above questionnaire had been pre-tested on family medicine residents at the Health Centre of Vyronas, Athens. During the main survey in the Medical School of Athens, the researchers directly administered the questionnaire to all medical students partici- pating in the September-November 2004 examination period. It was made clear that answering the questionnaire was optional and that the anonymity of respondents was guaranteed.

\section{Data analysis}

Three independent evaluators scored students' answers to open-ended questions, by identifying core themes and assigning them to categories. Some answers were assigned to multiple themes.

Statistical analyses included Pearson $\gamma^{2}$ and Fisher exact statistics where appropriate for categorical variables. The Mann-Whitney U statistic was also used for comparison of non-normally distributed continuous data. Results were considered statistically significant if the two-tailed p-value was less than 0.05. Data were analyzed using STATA ${ }^{\mathrm{TM}}$ (Version 8.0, Stata Corporation, College station, TX 77845, 800-782-8272).

\section{Results}

\section{Respondents' socio-demographic information}

Response rate was $82.5 \%$ with 1021 questionnaires out of 1237 completed and returned. Respondents' and nonrespondents' mean age and gender did not differ significantly ( $p>0.05$ ). Students coming from rural or semiurban areas of Greece were more likely to respond to the survey than students from urban areas $(58.2 \%$ versus $41.8 \%$, respectively; $\mathrm{p}=0.017$ ). Mean age of the respondents was 25.5 years, ranging between 23 and 38 years. Seven hundred seventy nine (779) $(76.3 \%)$ respondents came from major cities, whereas $242(23.7 \%)$ came from rural or semi-urban areas of Greece. A considerable percentage of the respondents $(31.4 \%)$ had a parent also working as a medical doctor. Only 44 out of the 1021 $(4.3 \%)$ respondents stated that GP/FM is -or could beamong their choices for specialty. No significant differences were observed by area of origin (i.e. urban versus semi-urban/rural) between the above group of potential General Practitioners ( $p G P s$ ) and the group of students who did not report GP/FM among their specialty choices (non-pGPs) ( $\mathrm{p}>0.05)$. However, the mean age differed significantly between the pGPs and the non-pGPs, with pGPs being the oldest ones (mean difference 3.6 years; $p$ $=0.012$ ). PGPs were found to be less literate regarding computer use compared to non-pGPs $(40.9 \%$ vs. $70.3 \%$, respectively, $\mathrm{p}<0.1$ ). The proportion reporting knowledge of a foreign language did not differ between the two groups $(\mathrm{p}=0.333)$.

\section{Medical specialty issues}

The proportion of medical students who reported having already chosen which specialty they would follow was $38.2 \%$. The most popular medical specialty was General Surgery $(10.9 \%)$, followed by Cardiology $(9.6 \%)$, Endo- 
crinology (8.7\%) and Obstetrics-Gynaecology (8.3\%). Only seven respondents (1.7\%) had already chosen GP/ FM as specialty. For those respondents who reported not being sure about their specialty, $(61.8 \%)$, Internal Medicine was the most favourite among their first choices (15.9\%), followed by General Surgery (11.2\%), Cardiology (8.7\%) and Neurology (7.4\%). Only twelve of those respondents stated that they might choose General Practice as a first choice (1.9\%). General Practice was also reported as a second choice for 8 of the undecided students $(1.3 \%)$.

\section{General Practice specialty issues}

The most common criterion for choosing a specialty among the pGPs was the guaranteed employment on completion of the residency (54.6\%), whereas scientific interest in the chosen specialty seemed to be the major criterion for the group of non-PGs (60.7\%). Better quality of life and lower chances for unemployment were two criteria that influenced the $9.8 \%$ and $6.5 \%$ of non-pGPs and the 11.4 and $54.5 \%$ of pGPs, respectively ( $\mathrm{p}<0.001)$ (Table 1). The main problem the respondents believed that they would confront during residency was dealing with bureaucratic issues for the pGPs $(72.7 \%)$ and having to work hard for the non-pGPs $(39.5 \%, \mathrm{p}=0.586)$. The majority of pGPs (79.5\%) stated that the present system of entering a residency course should remain as it is, whereas a $70.1 \%$ of the non-pGPs would prefer an examination system rather than the present one for entering the residency ( $p=0.179)$. Most of the pGPs $(75.2 \%)$ and the non-pGPs reported preferring to settle in an urban setting $(84.1 \%)(\mathrm{p}=0.181)$. Finally, a $18.2 \%$ of the pGPs and a $28.4 \%$ of the non-pGPs reported having already 'regretted' choosing medicine as a profession $(\mathrm{p}=0.139)$. The $\mathrm{pGPs}$ estimated that the need for medical doctors in Greece is around 75,000, while the rest of the respondents made a more conservative estimation of around 30,000 to $50,000,(\mathrm{p}=0.322)$. Forty three out of 1021 respondents $(4.2 \%)$ stated that they were not aware of GP/FM as a residency they could choose to follow in Greece (Table 2).
The major obstacle discouraging respondents from choosing GP/FM (59.2\%) as a specialty was reported to be the lack of specialization of this discipline, followed by perceived difficulty in finding a career post, low grade of acceptance by the medical community, and low social prestige $(14.8 \%, 13.7 \%$ and $12.3 \%$ respectively). The majority of medical students $(77.3 \%)$ stated that medical student experience on General Practice was either nonexistent or inadequate. Both pGPs and non pGPs shared the same opinion $(\mathrm{p}=0.074)$ (Table 3$)$. The main source of information for GP/FM for the whole sample of students was their fellow students $(76.9 \%)$, whereas the role of the University was rather limited (8.2\%) (Table 4). Both groups shared similar opinions on this subject ( $\mathrm{p}=$ 0.093 ). A $27.9 \%$ of the non pGPs has already regretted for his choice to follow a medical career, while a $18.2 \%$ of the pGPs had the same opinion ( $\mathrm{p}=0.157)$. Only $62.1 \%$ of the total sample of respondents knew the exact duration of the GP/FM residency; even a $27.3 \%$ of the pGPs gave a wrong answer to this question. A $65.2 \%$ of pGPs chose the right answer among the 4 proposed definitions for General Practice, while only $8.4 \%$ of the non pGPs answered correctly ( $\mathrm{p}<0.001)$. A significant $88.6 \%$ of pGPs were positive to the introduction of GP/FM as a curriculum course during University studies (Table 5), while $55.2 \%$ of the rest of medical students agreed to this ( $p<0.001)$. It should be stressed that $71.2 \%$ of those students who were against the introduction of GP in the university curriculum also reported that they found information on this medical specialty non existent or inadequate $(\mathrm{p}=0.031)$.

\section{Discussion}

The results of the present study were rather unexpected. The extremely low proportion of medical students reporting GP/FM among their specialty choices revealed a disappointing fact about the status of GP/FM in Greece. More precisely, only one student was determined to select GP/ FM for his residency program, whereas only 5 more of the respondents were considering it as one of it's choices. This proportion is rather disappointing compared to "tradi-

Table I: Students' criteria for choosing medical specialty

\begin{tabular}{|c|c|c|c|}
\hline \multirow[b]{2}{*}{ Criterion } & \multicolumn{2}{|c|}{ Possible specialty choice group } & \multirow[b]{2}{*}{ Total } \\
\hline & non-pGPs & pGPs & \\
\hline & N (Row \%) & N (Row \%) & $\mathbf{N}$ \\
\hline Short waiting time before admission for residency training program & $82(95.4)$ & $4(4.6)$ & 86 \\
\hline Particular scientific interest and skills & $593(99.2)$ & $5(0.8)$ & 598 \\
\hline High professional and social prestige & $101(97.1)$ & $3(2.9)$ & 104 \\
\hline Higher overall income & $42(93.3)$ & $3(6.7)$ & 45 \\
\hline Other & $159(84.6)$ & $29(15.4)$ & 188 \\
\hline Total & 977 (95.7) & $44(4.3)$ & 1021 \\
\hline
\end{tabular}

$p<0.001$ 
Table 2: Level of awareness of GP/FM as a specialty among students

\begin{tabular}{cccc}
\hline & \multicolumn{2}{c}{ Possible specialty choice group } & Total \\
\hline GP/FM awareness & non-pGPs & PGPs & N \\
& N (Row \%) & N (Row \%) & 43 \\
No & $43(100)$ & $0(0)$ & 978 \\
Yes & $934(95.5)$ & $44(4.5)$ & 1021 \\
Total & $977(95.7)$ & $44(4.3)$ & \\
\hline
\end{tabular}

$p=0.253$

tional" medical specialties, such as general surgery and internal medicine. Such low interest in GP/FM is significant since other studies have revealed that a student's initial career preference is an important predictor of what the student ultimately chooses as a career and that students tend not to switch into GP/FM if it was not being considered during the medical school $[18,19]$. Although General Practice was one of the major policy directions of the creation of the National Health System in the 1980's, and repeated efforts to introduce incentives for making this specialty attractive have been made, including, in 1997, almost automatic appointment to a tenured post in a Health Centre [20], GP/FM remains a choice of low priority in 2005. The medical model of health and illness still predominates, with GP/FM widely identified as 'inferior' to 'traditional' medicine (i.e. hospital and super-specialized medicine). The endurance of this model in Greece is no surprise since GP/FM has not received the needed support and promotion, 20 years after its recognition as a specialty. General Practice seems to be appreciated as an 'easy' medical specialty in Greece. Various factors have led to such an opinion, including political choices, fundamental differences in its residency program compared to any other medical specialty. All these reasons seem to shape an environment under which the medical students who perform poorly academically at the undergraduate level tend to be the ones to choose GP/FM as the easiest training choice. The above is also supported by the present results; students who identified GP/FM as one of their choices were less likely to be computer literate, more likely to be older and more likely (although not statistically significant) to be concerned about the ensured salary than the scientific interest of their profession, in contrast to the rest of the students who had selected a different specialty. Additionally, the pGPs reported not preferring an examination system for entering a residency, in contrast to the non-pGPs. If the percentage and quality of students interested in GP/FM is found to reflect the choice of GP/ FM as a residency and a profession, serious problems may eventually arise for the National Health System, taking into consideration the new model that is to be applied soon and which emphasizes Primary Health Care. The lack of any kind of information provided for choosing a specialty, either GP/FM or another one, should be also highlighted. For instance, a 73.3\% of nGPs and $83.3 \%$ of pGPs set the number of General Practitioners needed in Greece to less than 5000 instead of 8000 , as it is estimated by recent studies [20-22]. As it is reported, the Athens Medical School has not managed to provide adequate career information services that could help students choose the right medical specialty, according to ability, interest, need and personality factors and eventually to

Table 3: Students opinion on information provided about GP/FM in their University

\begin{tabular}{cccc}
\hline & \multicolumn{2}{c}{ Possible specialty choice group } & Total \\
\hline & non-pGPs & pGPs & N \\
\hline & N (Row \%) & N (Row \%) & \\
\hline Information provided & & & 345 \\
Non-existent & $337(94.9)$ & $18(5.1)$ & 444 \\
Inadequate & $411(94.7)$ & $23(5.3)$ & 179 \\
Satisfactory & $176(98.3)$ & $3(1.7)$ & 53 \\
Adequate & $53(100.0)$ & $0(0)$ & 1021 \\
Total & $977(95.7)$ & $44(4.3)$ & \\
\hline
\end{tabular}

$P=0.074$ 
Table 4: Source of information about GP/FM

\begin{tabular}{cccc}
\hline & \multicolumn{2}{c}{ Possible specialty choice group } & Total \\
\hline Source & non-pGPs & pGPs & N \\
\hline & N (Row \%) & N (Row \%) & 784 \\
Colleagues & $754(96.2)$ & $30(3.8)$ & 84 \\
University & $81(96.4)$ & $3(3.6)$ & 49 \\
Medical Journals & $45(91.8)$ & $4(8.2)$ & 24 \\
Internet & $21(87.5)$ & $3(12.5)$ & \\
Parents/relatives & $63(96.9)$ & $2(3.1)$ & \\
Other & $13(86.7)$ & $2(13.3)$ & 15 \\
Total & $977(95.7)$ & $44(4.3)$ & 1021 \\
\hline
\end{tabular}

$$
p=0.093
$$

inspire students towards GP/FM. And this, despite the fact that the Medical School of Athens has organised a series of career and speciality orientation seminars in the last couple of years. Furthermore, a new elective course inGeneral Practice will be offered as of the Academic year 20062007. Moreover, medical students are trained in GP/FM mainly from faculty coming from other medical specialties. This fact may have generated a 'hospitalized' way of medical thinking and by no means to the health promotion and disease prevention way of thinking that Primary Health Care services should centre upon. In conclusion we feel that based on the current study, systematic actions should be taken in medical schools in order to educate and recruit more medical students to GP. Such strategies could be university courses and programs about Primary Care and General Practice [23], spending more time in Community training rather than in hospitals, with General Practitioners, as educators $[24,25]$ and exposure to the General Practitioners' working model and rural practice at an undergraduate training level [5,26-32]. It is vital for GP recruitment and continuous education to introduce and fortify this medical specialty in the undergraduate medical curriculum, since as already stressed, exposure to GP during early university training leads to increased interest in it as a career choice [21,22]. Particularly for Greece, it seems that the first experiments on GP/FM residency have dramatically failed and that the main way for the improvement of the status of GP is to establish a university department, as is the case with all other medical specialties in the Greek Universities. This department should educate medical students in GP issues, recruit and train GP residents, offer post-graduate studies and care for the improvement of all Primary Health Care services in the country. The department of Social Medicine of the University of Crete, including the Division of Social and Family Medicine, has taken several initiatives in promoting undergraduate and postgraduate education and training in GP and in encouraging research in GP and Primary Health Care and has contributed substantially to the development of an active network between the Health Centres on the island of Crete $[33,34]$. The present study has several limitations, besides the low response rate achieved, indicative of the students' low interest in the subject. The Medical School of Athens, even though it is the largest [35], most popular and thus the one with the most competitive entry requirements, cannot be fully representative, something that is also evident from the distribution of the origin of the respondents which does not

Table 5: Students' interest on the possibility of introduction of a GP/FM course on their University curriculum

\begin{tabular}{cccc}
\hline & \multicolumn{2}{c}{ Possible specialty group } \\
\hline Would you be interested in the introduction of a GP/FM course? & non-pGPs & General Practitioners & Total \\
\hline & N (Row \%) & N (Row \%) & N \\
\hline No & $438(98.9)$ & $5(1.1)$ & $39(6.8)$ \\
Yes & $539(93.3)$ & 443 \\
Total & $977(95.7)$ & $44(4.3)$ & 1021 \\
\hline
\end{tabular}

$p<0.001$ 
reflect the total population [36]. It would be interesting to conduct similar studies in the other medical schools in Greece, with the additional aim of examining whether differences exist in the way that the medical students of the University of Crete view GP. Additionally, a large number of students participating to the study, although in their senior year, had not made their final choices in terms of their specialization. A follow-up after graduation and until finalization of their residency choice would shed further light on the matter and it is strongly recommended to be pursued in future research.

\section{Conclusion}

The professional status of GP/FM seems to be in a state of continuous crisis in Greece and much more has to be done in order to enhance GP/FM and put it higher on the list of priorities for specialization in medical students.

\section{Competing interests}

The author(s) declare that they have no competing interests.

\section{Authors' contributions}

AM conceived of the study, participated in its design and coordination and revised the manuscript.

CM conducted the statistical analysis, participated in its design and coordination, and drafted the manuscript.

AA participated in the design of the study, acquisition of data, analysis and interpretation of data, and revised the manuscript.

VG participated in the design of the study, acquisition, analysis and interpretation of data.

TM participated in the design of the study, acquisition, analysis and interpretation of data.

KM participated in the design of the study, acquisition, analysis and interpretation of data.

YT conceived of the study, participated in its design and coordination and revised the manuscript.

CS conceived of the study, participated in its design and coordination and revised the manuscript.

AP conceived of the study, participated in its design and coordination and revised the manuscript.

GC conceived of the study, participated in its design and coordination and revised the manuscript.

All authors read and approved the final manuscript.

\section{Acknowledgements}

We would like to thank and honour all General Practice residents trained at the Health Centre of Vyronas who participated and offered their precious time for the completion of this study. Additionally we would also like to thank all medical students who participated in the study and wish that our findings will aim in ameliorating their medical curricula.

\section{References}

I. Greek Ministry of Health [homepage on the Internet]: Health Map. [updated 2005] [http://www.mohaw.gr/gr/ygeia/index html].

2. Merkouris M: Evaluation of Health Systems. Primary Health Care 1987, 2, I:23-27. (In Greek)

3. Faculty of Medicine; University of Crete: Study Guide and Faculty Organisation, 1985 Heraklion (Greece) University of Crete 1985. (In Greek)

4. Philalithis A: Pre-graduate medical education in PHC at the Department of Social/Family Medicine, University of Crete. Proceedings of the national conference on Primary Health Care; loannina, Greece 200I. (In Greek)

5. Belos G, Lionis C, Fioretos M, Vlachonicolis J, Philalithis A: Clinical undergraduate training and assessment in primary health care: experiences gained from Crete, Greece. BMC Med Educ 5(1):13. 2005 May 9

6. Ontario Medical Association: OMA position paper on physician workforce policy and planning. Ont Med Rev 2002, 69(4): 17-28.

7. Canadian Resident Matching Service: Canadian resident match report 2002 Ottawa, Ont: Canadian Resident Matching Service; 2002.

8. Health Care in Canada: Health care in Canada Survey 2001 Toronto, Ont: Health Care in Canada; 200I.

9. Kasperski MJ: Where have all the family doctors gone? Response to the George Panel on Health Professional Human Resources Report. 200I [http://www.ocfp.on.ca/English/ OCFP/Communications/Publications/]. Toronto, Ont: Ontario College of Family Physicians

10. Jordan J, Brown JB, Russell G: Choosing family medicine. What influences medical students? Can Fam Physician 2003, 49: II3I- II37.

II. Wright B, Scott I, Woloschuk W, Brenneis F: Career choice of new medical students at three Canadian universities: family medicine versus specialty medicine. CMAJ 2004, I 70(13): I920-1924.

12. Skinner BD, Newton WP: A long-term perspective on family practice residency match success: 1984-1998. Fam Med 1999, 31 (8):559-65.

13. Kahn NB, Schmittling GT, Graham R: Results of the 1999 National Resident Matching Program: family practice. Fam Med 1999, $3 I(8): 55 I-8$.

14. Pugno PA, McPherson DS, Schmittling GT, Kahn NB: Results of the 2000 National Resident Matching Program: family practice. Fam Med 2000, 32(8):543-550.

15. Perfecture of Athens: Annual statistics, 2003 Athens (Greece); 2004

16. Kalra MG, Anand C, Shahi LG: The relevance of General Medicine Today: Role of Super-specialists vis-á-vis internists. JIACM 2003, 4(I): 14-7.

17. General secretariat of national statistical service of Greece. Athens: P_I. Population, surface and density by urban/rural areas [http:// www.statistics.gr]. (In Greek)

18. Curran $\mathrm{V}$, Rourke $\mathrm{J}$ : The role of medical education in the recruitment and retention of rural physicians. Medical Teacher 2004, 26(3):265-72.

19. Rosenblatt RA, Whitcomb ME, Cullen TJ, Lishner DM, Hart LG: Which medical schools produce rural physicians? Journal of the American Medical Association 1992, 268( ( 2): I 559-65.

20. Greek Union of General Practitioners [homepage on the Internet] Current National Legislation regarding GP L. 25/9/1997 [http:// www.enosigi.gr/nomothesia.htm]. (In Greek)

21. Smith Abel: Report on the Greek Health Services. Ministry of Heath and Social Welfare of Greece Athens: Pharmetica; 1994. (In Greek)

22. Gregory S, Liatsou M, Kyriopoulos Y: The optimal amount of Specialized Doctors and General Practitioners regarding population in Greece: Research with Delphi Panel. latriki 2002, 82(I):65-7I. (In Greek)

23. Hill-Sakurai Laura E, Schillinger Erika, Rittenhouse Diane R, et al.: Do Required Preclinical Courses With Family Physicians Encourage Interest In Family Medicine? Fam Med 2003, 35(8):579-584. 
24. Rourke JT, Incitti F, Rourke LL, Kennard M: Keeping family physicians in rural practice: solutions favoured by rural physicians and family medicine residents. Canadian Family Physician 2003, 49: I|42-II49.

25. Rourke JT: Politics Of Rural Health Care: Recruitment And Retention Of Physicians. Canadian Medical Association Journal I993, I 48(8): I $28|-| 284$.

26. Magnus JH, Tollan A: Rural doctor recruitment: does medical education in rural districts recruit doctors to rural areas? Medical Education 1993, 27(3):250-253.

27. Boulger JG: Family medicine education and rural health: a response to present and future needs. Journal of Rural Health |99|, 7(2): 105-II5.

28. Brazeau NK, Potts MJ, Hickner JM: The Upper Peninsula Program: a successful model for increasing primary care physicians in rural areas. Family Medicine 1990, 22(5):350-355.

29. Easterbrook M, Godwin M, Wilson R, Hodgetts G, Brown G, Pong R, Najgebauer E: Rural background and clinical rotations during medical training: effect on practice location. Canadian Medical Association Journal 1999, 160(8): I I59-1 I63.

30. Fryer GE Jr, Miyoshi TJ, Stine C, Krugman RD: Colorado's decentralized medical education to increase the number of graduates practicing primary care in rural areas. Academic Medicine 1993, 68(4):310-31I.

31. Stratton TD, Geller JM, Ludtke RL, Fickenscher KM: Effects of an expanded medical curriculum on the number of graduates practicing in a rural state. Academic Medicine 1991, 66:101-105.

32. Verby JE, Newell JP, Andresen SA, Swentko WM: Changing the medical school curriculum to improve patient access to primary care. Journal of the American Medical Association I99I, 266(I): II0-113.

33. Philalithis AE: Primary Health Care in Europe: 20+ years after Alma-Ata. In Health systems in the World: From evidence to policy. 5th FICOSSER General Conference Edited by: Kyriopoulos J. Athens: Papazisis Publishers; 2004:429-446.

34. Lionis C, Carelli F, Soler JK: Developing academic careers in family medicine within the Mediterranean setting. Fam Pract 2004, 2 I(5):477-8.

35. University of Athens. Medical School of Athens. [homepage on the Internet]. Premed Information sheet 2005 [http:// www.med.uoa.gr/odigosspoudwn.php]. (In Greek)

36. General Secretariat of National Statistic Service of Greece. [homepage on the Internet] Greece in numbers 2003 [http:// www.statistics.gr].

\section{Pre-publication history}

The pre-publication history for this paper can be accessed here:

http://www.biomedcentral.com/1472-6920/7/15/prepub

\section{Publish with Bio Med Central and every scientist can read your work free of charge}

"BioMed Central will be the most significant development for disseminating the results of biomedical research in our lifetime. "

Sir Paul Nurse, Cancer Research UK

Your research papers will be:

- available free of charge to the entire biomedical community

- peer reviewed and published immediately upon acceptance

- cited in PubMed and archived on PubMed Central

- yours - you keep the copyright
BioMedcentral 